\title{
Exploration of Student Nurses' Voices Regarding Self-Leadership in Clinical Learning at the Limpopo College of Nursing, South Africa
}

\author{
M. A. Mmakola ${ }^{1}$, T. M. Mothiba ${ }^{2} \&$ M. A. Bopape ${ }^{1}$ \\ ${ }^{1}$ Department of Nursing Science, University of Limpopo, South Africa \\ ${ }^{2}$ Faculty of Health Sciences, Dean's office, University of Limpopo, South Africa \\ Correspondence: Tebogo Mothiba, Faculty of Health Sciences, University of Limpopo, Private Bag X1106 \\ Sovenga 0727, South Africa. Tel: 27-15-268-2387.E-mail: tebogo.mothiba@ul.ac.za
}

Received: January 2, 2019 Accepted: February 2, 2019 Online Published: March 25, 2019

doi:10.5539/gjhs.v11n4p125

URL: https://doi.org/10.5539/gjhs.v11n4p125

\begin{abstract}
Background: Self-leadership is explained as a dynamic interaction of cognitive, behavioural and effective elements, geared towards self-influencing actions of an individual within the academic context. The purpose of this study was to determine the views of student nurses regarding self-leadership in clinical learning at the Limpopo College of nursing, South Africa
\end{abstract}

Objective: A non- probability, convenience, purposive sampling was used to select 16 students who voluntarily agreed to participate in this study. The researcher conducted semi-structured, one-to-one interviews which were audio recorded and transcribed. Data collection was done and analysed using the Tesch's inductive, descriptive coding technique.

Results: One theme and its sub-themes emerged namely: self-leadership associated with responsibility and accountability, self-leadership viewed as a learned strategy, self-leadership - a difficult act to achieve, self-leadership is a beneficial process during clinical learning periods and self-leadership viewed as the adoption of personal values

Conclusion: The findings of the study revealed that students shared the same views related to the enhancement of self-leadership in the clinical environment. In this regard, the various strategies were found to be used by students to support self-leadership learning.

Keywords: student nurses, student nurses' voices, self-leadership, leadership, clinical learning

\section{Introduction}

Leadership is a key skill required by all managers at all levels. Through the years, researchers have identified that managers' positions give them direct managerial responsibilities with which they tend to deal effectively with their roles (Frankel, 2008; Jooste, 2009; Reddy \& Jooste, 2015; Middleton, 2013). Some researchers have indicated that leadership skills are a pre-requisite for those who have recently qualified as practitioners and need to have confidence in order to offer leadership guidance to colleagues (Frankel, 2008; Jooste, 2009; Reddy \& Jooste, 2015) Nursing practice is at the point where it is crucial for clinical practitioners to possess leadership competencies necessary to reconfigure health care services that will ensure solutions for ever-changing the environment (Joseph $\&$ Huber, 2015). Therefore, all nurses should be equipped with the following characteristics of clinical expertise, effective communication, collaboration, coordination and interpersonal understanding (Scott \& Miles, 2013). Various researchers, over decades, have proposed varying explanations describing leadership within organizations (de Vries. Manfred \& Korotov, 2010; Jooste \& Mia, 2015; Stithyudhakarn, 2014). Most explain leadership as an individual-level skill which can be obtained through education (Frankel, 2008; Middleton, 2013; de Vries et al., 2010; Jooste \& Mia, 2015; Stithyudhakarn, 2014), while others describe it as a collective effort by members to accomplish organizational objectives (Reddy \& Jooste, 2015; Daft, 2005). They are all; however, in agreement, that leadership is necessary for the effective functioning of organizations, including health care institutions. According to Scott and Miles (2013), clinical leadership is a direct response to the complexity of managing patient care in the organizations with given economic constraints in a way that will promote continuous improvement and patient safety.

In today's health care institutions, the nurse's roles are becoming more autonomous, focused on outcomes and are 
characterized by high levels of accountability in leadership positions. This requires nurse leaders to respond to ever-changing healthcare needs, national policy framework and the impact of globalization on the provision of quality patient care. Therefore, leadership is a skill required to ensure quality nursing practices. Those entering nursing as a profession should be nurtured in leadership behaviours in order to adequately prepare them to provide high-quality care (Abdrbo, 2012). Furthermore, they should also be equipped with the following characteristics of clinical expertise, effective communication, collaboration, coordination and interpersonal understanding (Scott \& Miles, 2013). Furthermore, additional education, experience, engaging in practice narratives and stories can assist in the development of ongoing clinical leadership (Joseph \& Huber, 2015). There is a need to create a conducive learning environment and innovative teaching methods to instil the theoretical and practical concepts of leadership (Romeo, Kathleen, Dianne, Eraphie, Mark et al., 2016). Clinical nurse leaders are crucial to the success of patient care initiatives because good leaders help produce good care (Natashia, 2014).

The findings of a study on self-assessment of leadership behaviours suggested that leadership education should be integrated into the nursing education program (Abdrbo, 2012). Thus, leadership in nursing is regarded as an essential component of nursing practice and an integral aspect of a nurses' role (Pera \& Van Tonder, 2005). According to Jooste (2014), nurses need to develop skills that engage them in improving the health of patients and aspire them to lead in their environment. Therefore, leadership knowledge, skills, and abilities should be taught in nursing education programme to prepare student nurses for clinical leadership roles in healthcare settings (Joseph \& Huber, 2015). Furthermore, Havva and İlknur (2013) indicated that the nursing curriculum should also include leadership courses offering both theoretical knowledge and practice to equip students with leadership skills. Developing leadership skills among nurses in training is of critical importance because effective clinical leadership is associated with optimal hospital performance (Daly, Jackson, Mannix, Davidson, \& Hutchinson, 2014).

One of the strategic objectives stated in the National Strategic Plan for Nurse Education, Training and Practice (2012 - 2016) of the Republic of South Africa (RSA), is to enable strong leadership at all levels of nursing and midwifery practice. The Strategic Plan was formulated to deal with gaps affecting the provision of quality, safe patient care through the development of strong leadership within the nursing profession. Leadership attributes need to be instilled in nursing students in order for them to be able to develop self-leadership during the period of their training and beyond, thus leading to the provision of quality care to clients and patients (Jooste, 2014; van Zyl, 2012). The nursing curriculum should be developed in the way that it will allow nursing students to become nurse leaders equipped with skills and knowledge that will lead them to act in accordance with ethical principles and having effective communication skills necessary to improve nurse's image in the society and solve nurses' problems (Havva \& İlknur, 2013). Clinical nurse leadership education will assist in preparing nursing students for the opportunities to make improvements in healthcare systems that will have an impact on patients and families (Joseph \& Huber, 2015). It was against this background that the researchers were motivated to conduct this study to determine the views of students regarding self-leadership in clinical learning at the Limpopo College of Nursing, South Africa.

\section{Methods}

A qualitative explorative, descriptive and contextual research design was followed in this study with the aim of exploring and describing the views of student nurses regarding self-leadership during clinical learning at the Limpopo College of nursing.

In this study, the researchers chose a qualitative design because it allows for naturalistic interactions and promoted an understanding of views of student nurses regarding self-leadership in clinical learning (Grove, Gray, \& Burns, 2015).

The researcher collected descriptions of views of student nurses regarding self-leadership in clinical learning at the Limpopo College of nursing for the purpose of using the collected data to assess current conditions and to make suggestions for the improvement of self-leadership by students during clinical learning. The probing questions were asked because the researcher wanted to gain clarity or understanding of the situation based on the first response of the participants to the main question.

The researchers provided the participants with an opportunity to describe the phenomenon being studied in their own words. This assisted the researcher to acquire more information and knowledge regarding students' self-leadership characteristics and how the students led self towards learning in the clinical learning areas.

The researchers interviewed the participants at the clinical areas where the participants were requested to provide information related to the phenomenon under study in the context where it occurs. The study context is the clinical learning areas of the Limpopo College of Nursing. 
The population included all students in level IV of their training at the Limpopo College of Nursing. The total number of students per campus are as follows: Sovenga campus $(n=90)$, Thohoyandou campus $(n=70)$ and Giyani campus ( $n=90)$, giving an overall total of $n=250$ in the 2015 registration records.

A non- probability, convenience, purposive sampling method was used to select fifteen students willing to participate in this study. The researchers requested the list of all the level IV students from each individual campus's management.

The study was conducted at the Limpopo College of Nursing, which is the only nursing college within the Limpopo Province. The central office of the Limpopo College of Nursing is located at Polokwane City, with one central office and five campuses located in each district, i.e. Capricorn District, Sovenga Campus, which is $30 \mathrm{~km}$ east of Polokwane; Vhembe District, Thohoyandou Campus, which is $265 \mathrm{~km}$ North of Polokwane; Mopani District, Giyani Campus located 200km North East of Polokwane; Sekhukhune District, Sekhukhune Campus, which is $146 \mathrm{~km}$ South East of Polokwane and the Waterberg District, Waterberg Campus $38 \mathrm{~km}$ South of Polokwane. The Sekhukhune and Waterberg campuses are accredited to provide education and training for level I students and are the feeder campuses for the Sovenga, Thohoyandou and Giyani Campuses. It is within these three campuses that level IV students are based.

To ensure trustworthiness of the research data, Lincoln and Cuba's framework, as outlined in Polit and Beck (2008), was adhered to throughout the study. Strategies used to ensure trustworthiness of the research are credibility, transferability, dependability, and confirmability.

Ethical clearance was obtained from the University of Limpopo Turfloop Research Ethics Committee (TREC/64/2015: PG), Limpopo Provincial Department of Health and the Limpopo College of Nursing. Permission was obtained from all participants and their informed consent was obtained prior to each interview. The participants were ensured that their names would not be reflected in the study. Privacy, confidentiality, and fairness were maintained throughout the study and participants were also informed that they could withdraw their participation from the study at any time.

\section{Results}

The study findings revealed that the participants shared the same views of student nurses regarding self-leadership in clinical learning at the Limpopo College of nursing

Table 1. Theme and sub-themes

\begin{tabular}{ll}
\hline Theme & Sub-themes \\
\hline & 1.1. Self-leadership associated with responsibility and accountability \\
& 1.2. Self-leadership viewed as a learned strategy \\
1. Views of students related to the & 1.3. Self-leadership - a difficult act to achieve \\
concept of "self-leadership". & 1.4. Self-leadership is a beneficial process during clinical learning periods \\
& 1.5. Self-leadership viewed as the adoption of personal values \\
\hline
\end{tabular}

\section{Discussion}

The discussion of results is based on the theme that has emerged during data analysis and its sub-themes namely: self-leadership associated with responsibility and accountability, self-leadership viewed as a learned strategy, self-leadership - a difficult act to achieve, self-leadership is a beneficial process during clinical learning periods and self-leadership viewed as an adoption of personal values.

\section{Sub-theme 1.1: Self-leadership is associated with responsibility and accountability}

The study findings revealed that self-leadership is associated with responsibility and accountability. This was demonstrated by one participant indicating that the:

..."the ability of the individual to be able to perform a task and also be responsible for it, able to have outcomes that are desirable and control yourself and able to perform those tasks".

Another participant further indicated that self-leadership is:

..."being accountable for your actions that maybe with no help from another one, being your own leader, being your own self at your own time". 
The above was supported by another participant stating that:

"... are you able to be responsible for anything that you do especially in this job that we are in, able to ...to control people and also to delegate people if maybe you are a leader."

Responsibility is explained as the allocation and acceptance of instructions where everyone involved knows who does what. Accountability is a retroactive review of decisions that have been made, actions that have been carried out and how effective they were (Pera \& Van Tonder, 2005). The students assumed responsibility and accountability for their own learning.

Additionally, the findings of a study conducted by Jooste and Mia (2015) indicated that it is the responsibility of the students to undertake self-directed learning. As people learn about their own basic personality dimensions, they are able to learn to be positive and to develop confidence through self-leadership (Jooste \& Mia, 2015). According to Reddy and Jooste (2015), self-responsibility and knowledge contribute to self-leadership and are better demonstrated by individuals who are responsible and accountable for their own learning.

\section{Sub-theme 1.2: Self-leadership viewed as a learned strategy}

The findings of this study also revealed that self-leadership is viewed by most students as a learned strategy. The concept of "strategy" is explained as a plan of action designed to achieve long term goals or overall aims (Bezuidenhout, Garbers \& Potgieter, 2007).

Some of the participants reflected on self-leadership as a learned strategy by stating the following:

..."So self-leadership in my way it has to come from the inner you".

..."self-leadership is that, as a leader, you have to be able to act on your own even in the absence of a supervisor, make sure that you respect the values and mission of your work for example, you must always be punctual, have a good personal relationship with others, have good communication skills, be a good listener, advocate for patient's needs and then also be reliable".

Furthermore, one participant indicated that:

..."you have to do it yourself and you have to tell yourself that you think you are strong and you want to achieve this. It means I had to control myself so that I can be able to achieve that thing that I wanted to achieve".

The above statements concur with the findings of a study conducted by Edwards, Smith, Courtney, Finlayson and Chapman (2004), and supported by Valiga (2012), which revealed that knowledge and skills are needed in order to engage students in strategies that value the diversity of thoughts and ideas. These strategies should be geared towards the personal development of students by transforming acquired competencies into effective performances (Neshuka \& Justas, 2016). Therefore, participants learned self-leadership through introspection and reflecting on their learning abilities whilst in the clinical area.

\section{Sub-theme 1.3: Self-leadership is a difficult act to achieve}

The study findings revealed that self-leadership was a difficult act to achieve. This was reflected by a participant who stated that:

..."Leadership is not an easy job because like you are working with people, you would be telling them what to do even if they know what they here for. Once they start doing that job it is not easy to always follow people. Always to doing what they know they are here for at the clinical area so but it requires patience. Self-leadership, Ahh... let me say according to me is not an easy thing to do"

Another participant indicated that:

..."Self-leadership is something that is very much difficult but you are really willing to ahh ...to lead yourself and you know you can do that".

One of the strategic objectives stated in the National Strategic Plan for Nurse Education, Training and Practice (2012-2016) of the Republic of South Africa (RSA), is to enable strong leadership at all levels of nursing and midwifery practice. This followed the identification of gaps in leadership, affecting the provision of quality, safe patient care within the nursing profession. It is through this premise that the students should be taught leadership skills so that they can become effective leaders on completion of their education and training (Jooste, 2014).

\section{Sub-theme 1.4: Self-leadership is a beneficial process during clinical learning periods}

The study findings indicated that self-leadership was stated as a beneficial process during clinical learning periods and this was indicated by a participant who stated that: 
... "Self-leadership is, I can say a kind of a process which is so beneficial especially during the learning process because, without self-leadership, a student cannot manage to go through it all sometimes".

The same participant elaborated further by stating that:

... "During the time where routine work is not being done, self-leadership can be beneficial because we use our own time, spare time, to develop ourselves".

Another participant, in support of the above-mentioned participant, indicated that:

... "It will be important for our lectures when we move from the clinical area back to the classes, our lecturers should find out from each one of us if we have diaries were we wrote down what we have learned".

The findings of a study conducted by Hartman, Scott, and Miguel (2015) suggested that the goals with which students approach an educational experience may strongly influence the degree to which they learn. Therefore, self-leadership as a beneficial process is a form of practice-based learning based on experiential learning obtained by encouraging active participation of the students in their clinical learning through self-checks and writing of diaries (Andrew \& Ferguson, 2008). Therefore, the creation of an environment conducive to learning by students in clinical learning is paramount.

\section{Sub-theme 1.5: Self-leadership viewed as the adoption of personal values}

The study revealed that self-leadership was viewed as the adoption of personal values. This was indicated by a participant who said:

... "Self-leadership is knowing to control ahh ... yourself and then, I don't know how to put it, enhancing yourself about certain things that will help you in future to manage your life. Yes, not going astray".

Furthermore, one participant indicated that:

... "I can say self-leadership; it should be motivating yourself, knowing what you want. Actually taking a lead on your own without anyone pushing you. Just knowing your own perception".

The researcher's findings are supported by a study conducted by Waite, McKinney, Smith-Glasgow, and Meloy (2014) who confirm that students should learn that leadership is an inward and outward process, shaped by critical life events, culture and the social fabric of society. Students should be guided throughout their education and training by engaging them in self-leadership strategies such as self-observation, self-talk and mental imagery to promote self-efficacy (Lovelace, Manz, \& Alves, 2007). Self-efficacy contributes to the development of self-leadership skills within the students.

\section{Conclusion}

The students acknowledged that it was their responsibility and accountability for the achievement of their learning outcomes. Therefore, students need to be given continuous support to achieve self-responsibility and self-accountability by:

- Assisting students to learn to choose and engage in/among alternative activities to achieve their learning outcomes.

- Assisting students to establish their own learning outcomes while in clinical learning to complement programme outcomes and finding ways to achieve the set outcomes within the set time frame (van der Horst \& McDonald, 2008), under the guidance and supervision of the health professionals within the units/wards.

- Allowing students to identify those skills they would like to improve on and encouraging each student to develop their own plans for staying focused on the attainment of such skills (van der Horst \& McDonald, 2008).

- Assigning students relatively manageable tasks and gradually increasing the level of difficulty as they progress (van der Horst \& McDonald, 2008).

- Creating opportunities for participative learning to support the development of self-leadership among student from entry into the nursing programme until the completion of education and training of students at the Limpopo College of Nursing.

\section{Author Contributions}

MA conceptualization of the research data collection and analysis, TM conceptualization of the research, data collection, analysis and finalization of the research article, MA finalization of the research article. 


\section{Competing Interests Statement}

The authors declare that there are no competing or potential conflicts of interest.

\section{References}

Abdrbo, A. A. (2012). Self-assessment of leadership behavior among baccalaureate nursing students with different clinical training experience and nurses. International Conference on Management and Education, IPDR, 37. LACSIT Press, Singapore.

Andrew, N., \& Ferguson D. (2008). Constructing communities for learning, School for Health, Paper 104. Retrieved from http://researchonline.gcu.ac.uk/health/104, Accessed on 20/05/2016

Bezuidenhout, M., Garbers, C. J., \& Potgieter, S. (2007). Managing for healthy labour relations: A practical guide for health service in Southern Africa (2nd ed.). Van Schaik Publishers, South Africa

Daft, R. L. (2005). Leadership experience. International Student Edition. Thompson, South-Western, USA

Daly, J., Jackson, D, Mannix J, Davidson, P. M., \& Hutchinson, M. (2014).The importance of clinical leadership in the hospital setting. Journal of Healthcare Leadership, 6, 75-83. https://doi.org/10.2147/JHL.S46161

de Vries, Manfred, F. R., \& Korotov, K. (2010). Developing leaders: Leadership development on anthology on leadership development. INSEAD working paper, N0 2010/77/EFE/IGLC

Edwards, H., Smith, S., Courtney, M., Finlayson, K., \& Chapman, H. (2004). Impact of clinical placement location on nursing students' competence and preparedness for practice. Nurse Education Today, 24(4), 248-255. https://doi.org/10.1016/j.nedt.2004.01.003

Frankel, A. (2008). What leadership style should senior nurses' develop? Nursing Time, 104(35), 23-24.

Grove, S. K., Gray, J. R., \& Burns, N. (2015). Understanding nursing research: Building an evidence-based practice. Elsevier, Saunders. USA

Hartman, N. S., Scott, J. A., \& Miguel, R. F. (2015). An exploration of teaching methods used to develop leaders: Leadership educators' perceptions. Leadership and Organization Development Journal, 36(5), 454-472. https://doi.org/10.1108/DLO-08-2016-0080

Havva, Ö., \& İlknur, K. (2013). The opinions of nurse students regarding leadership in nursing (3rd ed.)

World Conference on Learning, Teaching and Educational Leadership. Social and Behavioral Sciences, 93, 111-115. https://doi.org/10.1016/j.sbspro.2013.09.161

Jooste, K. (2009). Leadership in health services management. Juta, South Africa

Jooste, K. (2014). Nurses' experiences on their self-leadership during a leadership development programme. African Journal for Physical, Health Education, Recreation and Dance, Supplement, 1(2), 467-483.

Joseph, M. L., \& Huber, D. L. (2015). Clinical leadership development and education for nurses: prospects and opportunities. Journal of healthcare leadership, 7, 55-64. https://doi.org/10.2147/JHL.S68071

Lovelace, K. J., Manz, C. C. \& Alves, J. C. (2007). Work stress and leadership development: The role of self-leadership, shared leadership, physical fitness and flows in managing demand and increased job control. Human Resource Management Review, 17, 374-387. https://doi.org/10.1016/j.hrmr.2007.08.001

Middleton, R. (2013). Active learning and leadership in an undergraduate curriculum: How effective is it for student learning and transition to practice? Nursing Education in Practice, 13, 83-88. https://doi.org/10.1016/j.nepr.2012.07.012

Natashia, J. S. (2014). Leadership in nursing: The importance of recognizing inherent values and attributes to secure a positive future for the profession. Collegian (2015), 22, 439-444. http://dx.doi.org/10.1016/j.colegn.2014.09.004

Neshuka, H., \& Justas, A. H. (2016). Description of an educational programme developed to support registered nurses during clinical supervision of student nurses in medical and surgical wards in a training health facility: Namibia. International Journal of Advance Nursing Studies, 5(1), 14-18. https://doi.org/10.14419/ijans.v5i1.5343

Pera, S. A., \& Van Tonder, S. (2005). Ethics in health care. Juta, South Africa.

Polit, D. F., \& Beck, C. T. (2008). Nursing research: Generating and assessing evidence for nursing practice. Wolters Kluwer Health. Lippincott Williams \& Wilkins 
Romeo, L. A. M., Kathleen, K. A. A, Dianne, E., Eraphie, A. T., Mark, J. D. R. B., ... Pascual, J. C. (2016). Leadership, Management and Team Competencies of Filipino Nursing Student Manager-Leaders: Implications on Nursing Education. International Journal of Nursing Science, 6(5), 109-116. https://doi.org/10.5923/j.nursing.20160605.01

Reddy, C. P., \& Jooste, K. (2015). Self-leadership behavior of clinical research nurses in the Southern Suburbs of Cape Town. African Journal for Physical, Health, Education, Recreation and Dance, Supplement, 1(2), 473-484

Scot, E. S., \& Miles, J. (2013). Advancing Leadership Capacity in Nursing. Nursing Administration Quarterly, 37(1), 77-82. https://doi.org/10.1097/NAQ.0b013e3182751998

Stithyudhakarn, S. (2014). A Study of leadership of nursing students at the Mission Faculty of Nursing, Asia-Pacific International University. Catalyst, 9(1), 31-42.

Valiga, T. (2012). Nursing education trends, future implications and predictions. Nursing Clinics of North America, 47, 423-434. https://doi.org/10.1016/j.cnur.2012.07.007

van Zyl, E. (2012). The relationship between self-leadership and certain personality traits among a group of first-line supervisors. Journal of Social Sciences, $31(2), \quad 159-165$. https://doi.org/10.1080/09718923.2012.11893024

Waite, R, McKinney, M. A., Smith-Glasgow, M. E., \& Meloy, F. A. (2014). The embodiment of authentic leadership. Journal of Professional Nursing, 30(4), 282-291. https://doi.org/10.1016/j.profnurs.2013.11.004

\section{Copyrights}

Copyright for this article is retained by the author(s), with first publication rights granted to the journal.

This is an open-access article distributed under the terms and conditions of the Creative Commons Attribution license (http://creativecommons.org/licenses/by/4.0/). 